\title{
Alterstice
}

Revue internationale de la recherche interculturelle

International Journal of Intercultural Research

Revista International de la Investigacion Intercultural

\section{Youth-voice driven after-school science clubs: A tool to develop new alliances in ethnically diverse communities in support of transformative learning for preservice teachers and youth}

\author{
Jrène Rahm, Annie Malo et Michel Lepage
}

Volume 6, numéro 1, 2016

Prendre en compte la diversité à l'école

URI : https://id.erudit.org/iderudit/1038277ar

DOI : https://doi.org/10.7202/1038277ar

Aller au sommaire du numéro

Éditeur(s)

Alterstice

ISSN

1923-919X (numérique)

Découvrir la revue

Citer cet article

Rahm, J., Malo, A. \& Lepage, M. (2016). Youth-voice driven after-school science clubs: A tool to develop new alliances in ethnically diverse communities in support of transformative learning for preservice teachers and youth. Alterstice, 6(1), 39-51. https://doi.org/10.7202/1038277ar

\section{Résumé de l'article}

In this paper, we draw on data collected in the context of a three-year action research project that involved the development of after-school science clubs in three high schools in ethnically diverse communities, made possible through a partnership between a university, the schools and the community. We document the evolution of a youth-voice driven science club over time and the kind of transformative learning it supported for youth who are for the most part first-generation immigrants growing up in an underserved urban centre. We also explore how the alliance between the university, the school and the community enriched the learning ecologies of the participating youth and how it was experienced by the instructors and preservice teachers who pursued service learning projects in the clubs as part of their university course work in education. We show how such diverse experiences offer rich insights into ways of building alliances among schools, community resources and the university to support equity-driven practices that are inclusive and supportive of ethnically diverse youth with complex immigration histories. 


\title{
7
}

\section{Youth-voice driven after-school science clubs: A tool to develop new alliances in ethnically diverse communities in support of transformative learning for preservice teachers and youth}

Jrène Rahm ${ }^{1}$, Annie Malo ${ }^{1}$ and Michel Lepage ${ }^{1}$

\begin{abstract}
In this paper, we draw on data collected in the context of a three-year action research project that involved the development of after-school science clubs in three high schools in ethnically diverse communities, made possible through a partnership between a university, the schools and the community. We document the evolution of a youth-voice driven science club over time and the kind of transformative learning it supported for youth who are for the most part first-generation immigrants growing up in an underserved urban centre. We also explore how the alliance between the university, the school and the community enriched the learning ecologies of the participating youth and how it was experienced by the instructors and preservice teachers who pursued service learning projects in the clubs as part of their university course work in education. We show how such diverse experiences offer rich insights into ways of building alliances among schools, community resources and the university to support equitydriven practices that are inclusive and supportive of ethnically diverse youth with complex immigration histories.
\end{abstract}

\section{Rattachement des auteurs \\ ${ }^{1}$ Université de Montréal, Montréal (Québec), Canada}

\section{Correspondence}

jrene.rahm@umontreal.ca

\section{Mots clés}

after-school science clubs, immigrant youth, teacher training

\section{Pour citer cet article}

Rahm, J., Malo, A. et Lepage, M. (2016). Youth-voice driven after-school science clubs: A tool to develop new alliances in ethnically diverse communities in support of transformative learning for preservice teachers and youth. Alterstice, 6(1), 39-52. 


\section{Introduction}

Youth-voice driven after-school science clubs are important venues for immigrant youth to engage with science and media in meaningful ways (Rahm, 2013). They also provide safe spaces for them to explore their history of immigration and aspirations for the future (Rahm, Lachaîne, Martel-Reny and Kanouté, 2012). They offer multilingual and transcultural children and youth opportunities to mobilize their funds of knowledge to support generative and transformative ways of learning and becoming (Tan and Calabrese Barton, 2012). Community programs and after-school science clubs also provide important settings for preservice teachers to make contact with youth with different histories from their own living in communities that are unknown to them. Through such placements, preservice teachers learn about immigrant students' lives, develop connections with their communities and families and gain an understanding of the rich funds of knowledge immigrant students bring to a learning situation (McDonald, Bowman and Brayko, 2013; Murrell, 2000). Few studies, however, have explored in detail how youth-voice driven after-school science clubs develop over time in urban centres and settings that serve a student body that is vastly diverse in terms of language, country of origin and immigration history. We also need to better understand how such settings and practices enrich the local learning ecologies of underserved communities and students with complex immigration histories, as well as others in adjacent universities who rarely venture into learning ecologies that are unfamiliar to them. We need to explore how youth-voice driven after-school science clubs mediate the development of alliances that support transformative learning for the involved youth and university students in education. The latter is particularly important given the extent to which most universitybased teacher education programs are still disconnected from practice (Zeichner, 2010a and 2010b). We also know that, in general, preservice teachers are not adequately prepared to respond to the academic struggles students experience as a result of cultural discontinuities tied to culture, language and histories that are quite different from their own (Potvin, Magnan and Larochelle-Audet, 2016). This is partially due to insufficient access to pedagogically sound programs in underserved communities for youth and preservice teachers (Murrell, 2000).

In this paper, we respond to these concerns in the context of an action research project that involved the development of after-school science clubs in three high schools in Montreal, Quebec, serving an ethnically diverse student population ( $80 \%$ refugee/first- or second-generation immigrant youth) in an urban centre. We first provide a brief description of the conceptual grounding of the study. We also summarize some of the pertinent literature on community-based teacher education. Following a description of our methods, we offer examples of transformative learning for both youth and preservice teachers, and then build on the results in the discussion.

\section{Transformative learning and community teacher education}

While after-school programming for immigrant youth in underserved communities is not new, its conceptual grounding in sociocultural theory comes with certain assumptions about learning, pedagogy and practice. Building on the work of the Fifth Dimension model, the clubs we developed were grounded in a commitment to equity in educational opportunities and a critical bicultural pedagogy and transworld mindset (Vasquez, Clark and Flores, 2014). We aimed to mobilize and build on the rich cultural experiences our diverse student body brought to the clubs, which is a form of cross-setting learning. We were attentive to local community needs and resources as we co-designed a science club built on student interest.

We encouraged a transcultural pedagogy in which students' histories, languages, and local sense of place were key resources for learning and practice. We purposefully worked against the "assimilationist function of schooling and the banking approach of learning" (Vasquez et al., 2014, p. 23), preferring to develop a practice driven by youth voice, dialogue and opportunities for expansive forms of engagement with science. We also worked against the disconnect that immigrant students often experience when they move from home to school and other settings (Gutiérrez, 2014). Like many others in the complex diaspora of Montreal, we wanted to challenge the discourse of unilingualism and uniculturism and instead celebrate, build on, and further expand our students' multiple complex histories and ways of knowing, being and becoming (Lamarre, 2013). Essentially, the aim of each club's "bilingual/bicultural sensibility" was to support "trajectories of possibilities for its children and university participants" (Gutiérrez, 2014, p. vii and ix). 
Inspired by Connected Learning Principles, we endorsed interest-powered learning that is peer-supported and academically oriented (Ito et al., 2013). We were committed to equity, social connection and full participation through the joint production of video science documentaries that could then be shared with the school and the community.

By developing alliances with community resources, the club offered youth learning environments that were usually inaccessible to them. In so doing, our goal was to support immigrant youth as they navigated a wide range of meaningful and empowering educational settings and practices-a second form of cross-setting learning (Ching, Santo, Hoadley and Peppler, 2015). Research suggests that first- and second-generation immigrant youth often lack access to a solid network of learning opportunities. In prior studies, immigrant parents had also expressed that engagement in after-school and summer activities was not a practice they were used to (Rahm, 2012; Rahm, 2013). It is exactly that kind of brokering work by parents, however, that is a part of growing up for most middle- and upper-class children in the Western world, leading to hyper-parenting in some cases, with most of children's free time taken up by structured extra-curricular activities (Barron, 2010; Gutiérrez, Izquierdo, \& Kremer-Sadlik, 2010). Lack of opportunities combined with lack of accessibility clearly puts immigrant youth in underserved communities at a disadvantage. It is this situation that led not only to the creation of the clubs, but also to an alliance and internship with the botanical garden and an engineering camp in the summer, as well as field trips to museums and parks during the school year.

The project was also a response to the current complex dynamic related to neoliberalism and globalization, which has resulted in a student body that is increasingly diverse ethnically, culturally and linguistically, while the student population in teacher education programs has become astonishingly homogenous: primarily white, middle-class and culturally mainstream (Murrell, 2000; Zeichner, 2010a). Neoliberalism's commodification of teacher education, with its emphasis on knowledge production, accountability and a technicist view of teachers, has further fuelled the disconnect between theory and practice. The result has been strong public criticism of university programs and the privatization of many teacher education programs in the United States (Coffey, 2010; Zeichner, 2010a\&b). Some universities have responded to these tensions by developing social justice and equity-driven teacher education programs in the community (McDonald et al., 2013). Research suggests that ongoing community placements in such programs help preservice teachers to develop a deeper understanding of the children, their community and student diversity. Such placements also offer a means of understanding schooling from a perspective outside of the actual school, which can foster an appreciation of the vast variety of learning contexts that students have to navigate. In making a case for teacher education in the community, Murrell (2000) introduced the term "community teacher," which he uses to refer to an individual who knows and values the community and its culture and mobilizes it in ways that support student learning. Community teachers typically live in the neighbourhoods where they teach, and are themselves products of public urban schools. They have a cultural, political and racial identity that naturally lends itself to equity-driven teaching. The Fifth Dimension model expands on these ideas by using a partnership model between the university and the community and placing students in after-school clubs in the context of community-oriented teacher education programs (Cole, 2006; Flores et al., 2014) or service-learning projects related to course work (Jurow, Tracy, Hotchkiss, and Kirshner, 2012). The partnership implies a two-way exchange between theory and practice, offering students opportunities to appropriate a transworld pedagogy by engaging in a bicultural exchange that helps them transcend borders that are new to them (Arreguin-Anderson \& Kennedy, 2014; Flores, Vasquez and Clark, 2014; Gutiérrez and Vossoughi, 2012). Club placements involve both service and learning (Coffey, 2010). Consequently, in this paper, we explore transformative learning as experienced by both youth and preservice teachers.

\section{Methodology}

We draw on qualitative data from one of the three clubs ${ }^{1}$ and its connected learning opportunities (summer internships), gathered over three years through visual ethnography, participant observation and interviews of all participants (2011-2014; Green, Skukauskaite and Cordova, 2007; Pink, 2001).

\footnotetext{
${ }^{1}$ The three clubs were situated in schools identified as high-poverty by the Minister of Education of Quebec.
} 
To document youths' transformative learning in the club, we relied on ethnographic video data and observations of its 20 90-minute club meetings during the second academic school year of the study (2012-2013, for a total of 15 hours of video data and 20 weeks of fieldnotes and journal reflections). That year, 12 students participated in the club (one girl and 11 boys between the ages of 13 and 14). The 12 youth came from several different countries: four from Sri Lanka, two from the Philippines and one each from Senegal, Vietnam, Algeria, Saudi Arabia, Morocco, Tunisia, and Cambodia. Three of the students were born in Canada, while the others had been in Canada for between two and 12 years. Eight of the 12 students were allophones and spoke three languages (their native tongue at home, English with their friends and French in school $^{2}$ ).

The two instructors from the university that year were both white: Issac, who identified as anglophone and middleclass and had just finished his master's degree in biology at a local primarily English university, and Myra, who identified as francophone and working class and was completing a master's degree in museology. Myra had been the club's facilitator the previous academic school year along with Ray (2011-2012), the instructor we focus on in the second part of the paper. Ray is white and identified as a middle-class English speaker, having grown up in western Canada. At the time, he was working on his professional master's degree in education at a local English university and took the opportunity to work at the club as part of a service-learning project for one of his courses. In order to document transformative learning for preservice teachers, we also analyzed 25 university students' reflections on their two visits to the club-a service-learning project the first author of this paper pursued in an undergraduate course on adolescent development. Two of the 25 students identified themselves as firstgeneration immigrants, one from Morocco and the other from Russia. The other students were white and selfidentified as working- and middle-class francophone Quebecers.

A content analysis was pursued of the fieldnotes for the five video projects the youth developed over eight weeks in the fall of 2012, the ten weeks of data collected in the context of the collaborative video project on deforestation in the winter of 2013, and the interviews (Spradley, 1979). To illustrate connected learning and transworld pedagogy in action, we crafted a story from Myra's fieldnotes of the two-week internship at the botanical garden in the summer of 2013 and focus group activity with the youth. To document transformative learning for preservice teachers, we pursued a content analysis of their reflections in class and their written course work. We also crafted a story of Ray based on his weekly fieldnotes, journal reflections and one semi-structured interview from the first year of the club (spring 2012).

\section{Results}

\section{A look at youths' transformative learning in the club}

We started the first video project with a discussion and brainstorming session about topics the youth wanted to work on in teams in their first video documentary. One team, Talish and Kyle, was interested in frogs and wanted to show how they live and how their respiratory system works. They prepared questions for the ecologist who visited the club the following week: "How do frogs breathe? Why do frogs also need to keep their body and eyes wet? Why do they hatch their eggs in the water? Why are people often afraid of frogs? How are eggs fertilized? What is the difference between frogs and toads?" They also conducted a literature review on the web, looking for information on the reproductive system of frogs, different images of frogs and the life cycle of frogs. They started their video editing using the documents they had collected. The following week they videotaped their interview with a visiting scientist, parts of which they integrated into their documentary. They also handled frogs the scientist brought to the club. Their final video, which was four minutes long, contained a combination of images and messages, as shown in Figure 1.

\footnotetext{
2 Bill 101, introduced in 1977 in Quebec, made French the official language of the province, stipulating that all children under 16 receive their primary and secondary education in French schools, unless one of the child's parents had received most of their education in English in Canada, or the child had already received a substantial part of his or her own education in English in Canada.
} 
Figure 1. Summary of video documentary on Frogs

\begin{tabular}{|l|l|l|}
\hline Example of image & Content & Sound and special effects \\
\hline & $\begin{array}{l}\text { Introduction to frogs } \\
\text { Announcement that they belong to the } \\
\text { amphibian family - Images of goliath frog } \\
\text { in Africa - Note that most frogs live in } \\
\text { Africa }\end{array}$ & $\begin{array}{l}\text { Music as Kyle announces the presentation } \\
\text { with many special effects, followed by } \\
\text { Talish joking that “If you don't watch out, } \\
\text { the frogs will attack you!" }\end{array}$ \\
\hline & $\begin{array}{l}\text { How do frogs breathe? } \\
\text { Why do frogs lay their eggs in the water? } \\
\text { How are the eggs fertilized? } \\
\text { How many eggs do they lay each time? }\end{array}$ & $\begin{array}{l}\text { A video mix with a scientist explaining how } \\
\text { frogs' respiration system works, with } \\
\text { some background music. Explanation of } \\
\text { fertilization with images as the boys take } \\
\text { turns speaking. }\end{array}$ \\
\hline
\end{tabular}

Talish, originally from Sri Lanka, had been in Montreal for 11 years at the time of the study. He spoke Tamil at home and English most of the time with his friends. Although he struggled in school academically and was often absent because of health issues, he enjoyed the club and was one of the few youth who participated for two consecutive years. Kyle was born in Montreal, but his parents were from the Philippines, speaking Tagalog and English with him at home. Kyle remembered how stressful it was for him to start school, coming face to face with French for the first time. Kyle liked science and really enjoyed the club because he could engage with science "without constraints" and pursue his interests with friends he met through the club and with instructors who were "like friends" to him. The club was not only an important venue for the development of his science and technology expertise, but also provided him with support as he travelled through different "linguistic zones" (Lamarre, 2013).

Another team, led by Kevin, was really interested in technology and computers. Kevin was from Vietnam, and his teammates had been born in Montreal to parents who came from Cambodia and China. The three ended up talking to a technician from the university, gathering information that they transformed into a comprehensive storyline that scrolled by with a musical soundtrack while they took turns providing the narration. They had prepared various questions for the interview, including: "What happens when you put two memory cards into a computer? How does a virus in a computer work? How does a mouse work? How does a computer work? How does the electrical supply system work? Why are there games that don't work? Why are there different kinds of hard drives while their REM is usually not that different?" Their clip ended with some special effects and the photographs the boys had taken of transportation in their community during a photography workshop-the result being an interesting mix of multiple resources and personal productions that they were obviously very proud of.

A total of five documentaries were produced on the following themes: Frogs, Extinction, Canids and Predators, Technology of Today, and Caffeine and its Effects on the Human Body. After watching them together, we talked about what youth had enjoyed the most about the video production process. Talish and Kyle liked editing the video and being in charge of that process: "We can choose the title, or what we want to put in, it's all really us...yes, no constraints." They also enjoyed adding a personal and creative touch to their documentary through special effects and the addition of the Star Wars theme. The ecologist's visit gave them an opportunity to handle a frog, a 
salamander and some snakes, which sparked Kyle's interest in caring for animals. Both boys also participated in the summer internship program at the botanical garden, where they ended up observing frogs and toads in nature. That kind of a cross-setting connection is an illustration of meaningful learning that can result in deeper forms of engagement with a topic of interest to youth (Rahm, 2012; Bell et al., 2013). Talish, for example, bought himself a magnifying glass at the botanical garden so that he could pursue the study of insects and animals on his own time. As allophones (with a few exceptions), the youth also valued cross-setting connections to improve and practise their linguistic repertoires and affirm their multilingual identities (Lamarre, 2013). For instance, Kevin noted how talking to a technician about computers and then transforming that information into a storyline for the documentary helped him "communicate more and better." They also valued becoming more skilled in the creative use of technology.

The club offered the young people a form of engagement with science and technology that they enjoyed and that was quite different from the heavily charged science curriculum at their school. As one participant noted, "In science class we always do worksheets, each time on something different. In the club we did projects and many related activities and topics. I like the science club better than science class." One of the instructors felt that the club helped them "think about bigger subjects, and just taking the time to think about different issues, especially when it comes to science, be more open-minded about stuff and critical, ask questions." We engaged in a great deal of dialogue in the club and worked on topics over long periods of time. For example, as we prepared the second video production on deforestation, we encouraged club members to reflect on what they had learned from gathering information on the Internet:

\footnotetext{
Moustapha: The most interesting thing I found [giggles and moves around on his chair, makes everybody giggle] it's... the behaviour towards the human...

Instructor: What do you mean by "behaviour"?

Moustapha: Kind of like, you know, when humans level the forest, after it's like they lose their habitat, so... that's it!

Jian: What I learned is, like, when there are a lot of moose... no, they are elks (...) and when (...) there is more wolves or moose than wolves... [struggling to articulate his idea]
}

Note how challenging it was for them to articulate their ideas. Moustapha was struck by the fact that humans destroy important animal habitats by deforestation without ever seeing it as a selfish act. Jian appeared to understand the systemic relationship between wolves and moose (or elks) and population density, which suggested that he was slowly developing an understanding of how an ecosystem works. While participants had opportunities to appropriate scientific language which seemed challenging to all of them-not just the allophones-they also learned a lot about natural science through our focus on biodiversity and the second video project on deforestation. Our dialogue sessions gave club members opportunities to develop their own point of view on these controversial issues and enrich their knowledge of science (Wassell, Martin and Scantlebury, 2013). As shown in Figure 2, it led to a video documentary on deforestation, co-produced by the whole group. The final production shows Yassine on stage with the scientist interviewing the ecologist and expanding on questions his team had developed, woven together with other sections on topics participants cared about, like the brief coverage of the puma at the end of the clip. 
Figure 2. Summary of video documentary on Deforestation

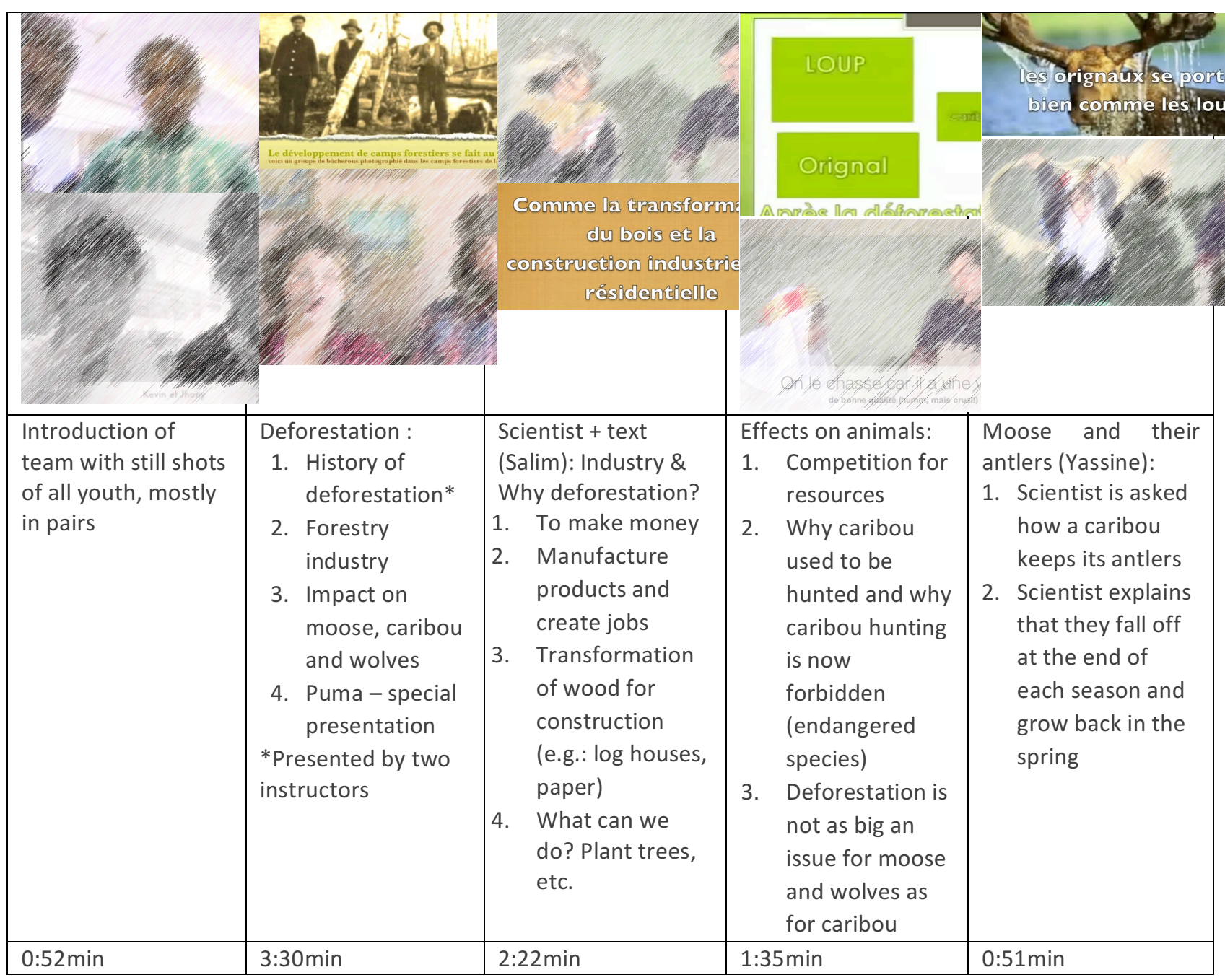

Later, Yassine found it difficult to see himself in the video and asked "to erase his face." He was concerned that during a screening session others "laughed at [him]." The instructor tried to put things into perspective: "We didn't laugh at you, we laughed because it was funny! We weren't laughing at you, so you shouldn't take it personally." She added, "You were clowning around, it was funny! You were having fun and you were, you were, like, dressed up, disguised, and it was to make everybody laugh." Eventually, Yassine accepted his role as a video producer and "clown in the script." This anecdote shows how club activities and respectful relationships led to the emergence of important learning opportunities in a community supportive of youth agency (Wassell et al., 2013). The example illustrates that even though Yassine was more fluent in French than his allophone peers in the club, he struggled with speaking up and assuming the role of a video producer.

\section{Connected learning and transworld pedagogy in action}

To create additional learning opportunities and make the most of our role as "brokers for learning" (Ching et al., 2015), we organized a two-week internship for the youth at a summer camp at the botanical garden in the summer of 2013. The participants' role was to help with various camp activities aimed primarily at elementary school children. Each morning, we took the subway with the youth to the botanical garden at the other end of the city. While we strongly believed in these kinds of "brokering" activities, it became evident to us just how inaccessible so many summer activities are to immigrant youth, as explained in Myra's reflection: 
Today was our first day and it was so interesting to see how the children in summer camp in the botanical garden interacted with the youth from our science club. What I noticed most is the contrast between them in terms of their cultural background and socioeconomic status. On the one hand, the campers are dressed and act in ways that gives them away as primarily middle- and upper-class and well educated Quebecers, with little visible ethnic diversity, speaking an impeccable French, nicely dressed, calm and eager to perform well and be noticed. In contrast, our youth from the science club struggle to express themselves well in French, are very shy in the garden when asked to speak up in front of the others, but laugh a lot and at times are off-task and noisy when among themselves. They use a lot of gestures and are quite fraternal. (Reflective Notes, Myra, July 1, 2015)

Few of the youth we worked with had ever participated in a summer camp. Some spent their summers sitting at home, hanging out or playing in nearby parks, while others visited families in other cities in Canada or the United States. Still others returned to their home country every summer. Lack of financial resources and the difficulty of reconciling jobs and summer camp schedules were other barriers to participation youth mentioned. That kind of complex mobility and history posed a challenge to their integration in the activities as assistants as well. Many activities were new to them. As a consequence, Myra took on the role as a broker of learning opportunities in the garden for "our" youth:

The campers were eating blackberries directly off the bushes in the blackberry patch today. Our three youth were sitting with me, somewhat discouraged from the heat in the garden. I encouraged them to go and taste the blackberries. They told me they never tasted them before but would be interested in finding out how they taste. I asked one of the campers, a young girl, to bring us some blackberries to taste. She was all excited to share and watch us taste them. The camp assistant was shocked to learn that our youth had never tasted blackberries: "What? They don't know what a blackberry is?" At first, Kyle, one of the youth refused to eat anything that came from a tree or a bush in the garden. Yassine, another youth was worried that it might be poisonous but in the end tasted it anyway. Moustapha, another youth assistant, then spent the rest of the day going back, eating more blackberries. He even asked to bring some home for his mother. [Field Notes, Myra, July $1,2013]$

The learning opportunity was not "noticed" by the youth because blackberries were not a part of their history and cultural repertoires. Yet, Myra had developed the kind of cultural sensitivity needed to re-mediate that opportunity in ways to support club members' transformative learning. In so doing, she created new possibilities and opportunities for learning, not simply for the youth but for the camp instructors as well. Later, as we reflected with youth about the kind of transformative learning the internship had made available to them, Talish noted how much he had enjoyed catching insects and being in nature, whereas Kyle talked about having the opportunity to touch a frog, garden and plant some herbs. Others enjoyed being in the garden, felt comfortable in nature and valued the feeling of being respected by the others and "talking with everybody." It was transformative for our youth to get to know children who were quite different from them yet respectful of them in a natural learning environment.

\section{Ways to engage student teachers in transformative learning}

\section{Quotes from reflection notes written by preservice teachers}

I discovered a multicultural school, something I did not know before.

My observations helped me to come into contact with ethnically diverse youth since I come from a primarily white, québécois neighbourhood.

It helped me undo some of my prejudices about youth of another culture.

I enjoyed watching the youth work together in a shared project.

I thought a science club in a school juggling many difficulties would never work. And I was happy to see that it did!

Even though it is an after-school activity, youth were interested in science and the projects. I didn't expect that. I also noticed that the students were already quite critical. 
These quotes from the preservice teachers who visited our clubs on two occasions as part of a course assignment in their teacher education program underline the importance of undoing preconceived notions about immigrant youth and ethnically diverse communities and schools. What we engaged in was another form of "brokering learning opportunities." The quotes clearly illustrate the kinds of images student teachers bring to their education about ethnically diverse schools and youth and their own history, deeply grounded in a myth of the monolingual classroom that in most cases prohibits transformative learning. The organization of preservice activities in settings the students would otherwise not venture into is clearly important (Onore \& Gildin, 2010; Murrell, 2000), as the following reflection by a student teacher suggests:

When I entered the school I felt like a stranger, which is in part what I expected. And then, the youth were very friendly and welcoming and were not challenged in any way by our presence. The school itself was very colourful: the walls are all painted in colours and covered with posters of all kinds. What surprised me the most is the absence of windows in that school which made me think of a prison. But the students we saw in the hallways seemed happy, were laughing and having a good time even saying hello to us. I was expecting a different kind of school, run-down and poor, a vision of a school in a poor and ethnically diverse neighbourhood that I have to undo. Everything I saw was a surprise to me and challenged me to think otherwise. [Written reflection by student teacher $\mathrm{A}$ ]

The challenge for a teacher education program, then, is to engage with these visions of schools and youth in underserved and ethnically diverse communities and help student teachers develop other ways of seeing and relating to youth of colour (Coffey, 2009; Hallman, 2012). Ray's story offers another illustration of that process:

...the diversity in this school was amazing; I've never really seen that, just so many students from other backgrounds and culture. And I felt really welcome, I mean I'm kind of the funny guy, I mean they laugh at my accent, but they do it really nicely, and it kind of creates a bond, it's our way of connecting; they make fun of my accent, but in a good-hearted way. So I felt really welcomed in the club, the teachers were really welcoming, and especially considering I'm not... like, sometimes they come up and they say something, and it's too fast and I don't get the accent, and people are quite understanding. [Interview, Ray, 2012]

Ray's own struggles with French as a second language helped him to experience first-hand what a transworld pedagogy implies, such as being respectful of each other and building on one another's strengths. He also found the connections with his teacher education coursework offered by his teaching experience in the club extremely valuable:

I think the really important thing for me was linking it to my classes and having read the kind of "radical" literature, alternative literature to the academic writing that's evidence based, that kind of gave me the confidence for teaching and being able to implement it. That was really big. (Interview, Ray, 2012]

Implementing a youth-voice centred pedagogy and taking on the role of mentor and guide throughout the project was challenging, however. Ray was surprised by how much guidance the students needed. He also overcame his own preconceived ideas about technology "'cause at the beginning that scared me. I was, like, how am I gonna do this? I don't even know how to use that stuff [i-Movie software]!"

Two of Ray's courses in his teacher education program overlapped with his work in the club and its underlying philosophy: one course in neoliberal education and another on science education. The latter focused strongly on the idea of using students' interest in science as a starting point instead of sticking to a predetermined curriculum. Although Ray saw this as a huge challenge in a regular classroom of about 28 students, it was something he could pursue in the context of the club:

It was amazing to me to have the background to kind of try to create a space where I can have those conversations and not say what I think they should do, but instead have the opportunity to say, "What are you really interested in, what's concerning you these days, what do you wanna learn about?" and by doing so, reinforce that idea that "this could be science!" (Interview, Ray, 2012) 
Ray's experience in the club not only led to a deep appreciation of a youth-centred pedagogy, but also helped him question the objectives of science education and what can be considered as "science." Ray was able to see beyond the video production as the key objective of the activity and appreciate the educational process behind its production:

...the goal was the process and the interactions we had, and having them think of science differently and to think of ways I can do science, that was always my goal... So in the end, I mean, if the video is mind-blowingly amazing, that's great, but if it's not, as long as I know that they did it, or they came up with something, that's what's important. (Interview, Ray, 2012)

Even though Ray wondered how he could apply a similar pedagogy in a classroom setting with more students, the club helped him to reflect on his future position as a science teacher and the kinds of practices he might try to foster in his classroom:

...the club is really cool, to get outside of the curriculum, to really try to think about what science is and can be, and that also connected nicely with my course in science education, where we discussed that science is a lot more than what scientific and math textbooks tell us. So having that conversation at the university and then seeing it in practice was really cool. [Interview, Ray, 2012]

The opportunity to teach in an after-school setting provided a way to get to know youth of colour who, although they were struggling academically, brought rich cultural knowledge to the science practice-resulting in transformative learning for Ray (Hallman, 2012). He gained a better understanding of the cultural processes of learning and what it means when children and teachers construct the curriculum together (Jurow et al., 2012). He also developed a deep appreciation for the type of learning that occurs outside of the classroom (McDonald et al., 2013).

\section{Discussion}

The field trips were, like, the best ... and my mother encouraged me to go on the field trip and see with my own eyes instead of just talking about it in class... or in the botanical garden it was amazing, it felt like in a real forest even though I was still in the city. (Vishmy, youth participant)

The above quote and results offer rich insights into why cross-setting learning and alliances matter, especially when grounded in a transworld pedagogy that synchronizes multiple worlds in respectful and meaningful ways, supporting transformative learning for both youth and preservice teachers. As Vishmy's comment also shows, that kind of learning was new and engaging for the youth and preservice teachers we worked with, leading to transformations in how they saw themselves as learners and what learning science and technology could involve (Barron et al., 2014). For the student teachers, the internship or coursework provided a means to engage with multilingual students and confront a reality they were unfamiliar with (Lamarre, 2013). The project also showed students how alliances among multiple educational settings and practices can enrich and support cross-setting learning (Barron et al., 2014; Bell et al., 2013). It helped student teachers develop alliances with ethnically diverse youth, schools and after-school settings and informal science venues that were supportive of youth learning and becoming.

Like Murrell (2010), Onore and Gildin (2010) call for a positioning of teachers as public professionals or "community teachers" who see their work as "facets of the same work that is carried out by parents, cultural and religious organizations, and social service agencies" (p. 29). These teachers consider themselves to be engaged in a collaborative, collective project that is making a significant contribution to community development. They become key players in a networked community of educators. This shift in perspective needs to be developed in teacher education programs at universities. It would make evident their commitment to equity and inclusive practices in education. Skinner (2010) refers to it as a means to transform "teacher education from the inside out." McGregor, Sanford and Hopper (2010) see it as a way to move beyond simple apprenticeship into the profession, with such placements offering preservice teachers opportunities for civic, social and political engagement-essential literacies for teaching in the 21st century. Ray's story also points to the value of a close alignment between theory (i.e., course readings at the university) and practice (i.e., placements). By forging the types of alliances between 
programs and educational settings that we attempted to create with our project by brokering and working at the intersection of language, culture, technology and science, we not only supported youth-voice driven learning but contributed to the development of the social capital of youth and preservice teachers (Ching et al., 2015). The study clearly shows that although alliances between educational resources and settings matter, they are not enough. As Jurow et al. (2012) noted, "being an effective teacher means being an effective learner" (p. 159). It is time to take up the challenge of creating networks for learning with youth, families, communities and university students that are grounded in a vision of teaching as a community endeavour characterized by cooperation and mutual respect. Future research must explore the types of alliances and dialogue among student teachers, the community and the university that are most conducive to the "criticality and ongoing inquiry" that is focused on children and their families (McGregor et al., 2010; Murrell, 2000). Preservice teachers also need opportunities to engage more deeply with ways to translate community practices into school contexts (for example, how to build on student interests in the classroom). Finding ways to support the kind of transformative learning that results in empowering and equity-driven educational pratices where underserved ethnically diverse children, families and communities have a voice is the challenge that the Fifth Dimension Model has continually responded to through its profound commitment to alliances. We would do well to build on it further to disrupt rigid forms of learning for both youth and preservice teachers.

\section{Acknowledgements}

The authors wish to thank all the students, parents, teachers, schools, and community organizations involved for their participation. This study was made possible thanks to funding from the Fonds Société et culture and its partner, the Ministère de l'Éducation et de l'Enseignement supérieur (MEES) du Québec, through its Programme de recherche sur la persévérance et la réussite scolaires.

\section{References}

Arreguin-Anderson, M. G., and Kennedy, K. D. (2014). Aspirantes' Consejos on El Maga and the role of technology. In B. B. Flores, O. A. Vasquez \& E. R. Clark (Eds.), Generating transworld pedagogy (pp. 117-127). New York, NY: Lexington Books.

Barron, B. (2010). Conceptualizing and tracing learning pathways over time and setting. Yearbook of the National Society for the Study of Education, 109(1), 113-127.

Barron, B., Gomez, K., Pinkard, N., and Martin, C. K. (2014). The digital youth network. Cultivating digital media citizenship in urban communities. Cambridge, MA: MIT Press.

Bell, P., Bricker, L., Reeve, S., Zimmerman, H. T., and Tzou, C. (2013). Discovering and supporting successful learning pathways of youth in and out of school: Accounting for the development of everyday expertise across settings. In B. Bevan, P. Bell, R. Stevens, \& A. Razfar (Eds.), LOST opportunities: Learning in out-of-school time (pp. 119-140). New York, NY: Springer.

Ching, D., Santo, R., Hoadley, C., and Peppler, K. (2015). On-ramps, lane changes, detours and destinations: Building connected learning pathways in Hive NYC through brokering future learning opportunities. Document retrieved from: http://hivenyc.org/

Coffey, H. (2009). "They taught me": The benefits of early community-based field experiences in teacher education. Teaching and Teacher Education, 26, 335-342.

Cole, M. (and the Distributed Literacy Consortium) (2006). The Fifth Dimension: An after-school program built on diversity. New York: Russell Sage Foundation.

Flores, B. B., Vasquez, O. A., Clark, E. R. (Eds.) (2014). Generating transworld pedagogy. New York, NY: Lexington Books.

Green, J., Skukauskaite, A., and Cordova, R. (2007). Epistemological issues in the analysis of video records: Interactional ethnography as a logic of inquiry. In R. Goldman, P. Pea, B. Barron, \& S. J. Derry (Eds), Video research in the learning sciences (pp. 115-132). Mahwah, NJ: Lawrence Erlbaum Associates. 
Gutiérrez, K. D., and Vossoughi, S. (2012). Lifting off the ground to return anew: Mediated praxis, transformative learning, and social design experiments. Journal of Teacher Education, 61(1-2), 100-117.

Gutiérrez, K., Izquierdo, C., and Kremer-Sadlik, T. (2010). Middle class working families' beliefs and engagement in children's extra-curricular activities: The social organization of children's future. The International Journal of Learning, 17(3), 633-656).

Gutiérrrez, K. D. (2014). Foreword: La Clase Magica: An enduring prototype of a new Latin@ Diaspora. In B. B. Flores, O. A. Vasquez \& E. R. Clark (Eds.), Generating transworld pedagogy (pp. vii-xii). New York, NY: Lexington Books.

Hallman, H.L. (2012). Community-based field experiences in teacher education: Possibilities for a pedagogical third space. Teaching Education, 23, 241-263.

Ito, M., Guitérrez, K. Livingstone, S., Penuel, B., Rhodes, J., Salen, K., Schor, J., Sefton-Green, J., Watkins, S. C. (Eds.). (2013). Connected learning: An agenda for research and design. A research synthesis report of the Connected Learning Research Network. Retrieved from: http://connectedlearning.tv/what-is-connected-learning

Jurow, A.S., Tracy, R., Hotchkiss, J.S., \& Kirshner, B. (2012). Designing for the future: How the Learning Sciences can inform the trajectories of preservice teachers. Journal of Teacher Education, 63, 147-160.

Lamarre, P. (2013). Catching "Montréal on the move" and challenging the discourse of unilingualism in Québec. Anthropologica, 55(1), 41-56.

McDonald, M. A., Bowman, M., and Brayko, K. (2013). Learning to see students: Opportunities to develop relational practices of teaching through community-based placements in teacher education. Teachers College Record, $115(4), 1-35$.

McGregor, C., Sanford, K., and Hopper, T. (2010). <Alter>ing experiences in the field: Next practices. In T. Falkenberg and H. Smits (Eds.), Field experiences in the context of reform of Canadian teacher education programs (2 vols., pp. 297-315). Winnipeg, MB: Faculty of Education of the University of Manitoba.

Murrell, P. C. (2000). Community Teachers: A Conceptual Framework for Preparing Exemplary Urban Teachers, The Journal of Negro Education, 69(4), 338-348.

Onore, C., \& Gildin, B. (2010). Preparing urban teachers as public professionals through a University-Community Partnership. Teacher Education Quarterly, 37, 27-44. (EJ902707)

Potvin, M., Magnan, M.-O., and Larochelle-Audet, J. (2016). La diversité ethnoculturelle, religieuse et linguistique en éducation. Montréal, Canada: Fides Éducation.

Pink, S. (2001). Doing visual ethnography. Thousand Oaks, CA: Sage.

Rahm, J. (2013). Collaborative imaginaries and multi-sited ethnography: Space-time dimensions of engagement in an after-school science program for girls. Ethnography and Education, 7(2), 247-264.

Rahm, J., Lachaîne, A., Martel-Reny, M.-P. et Kanouté, F. (2012). Le rôle des organismes communautaires dans la réussite scolaire et le développement identitaire des jeunes issus de l'immigration. Diversité Urbaine, 12(1), 87-104.

Spradley, J. P. (1979). The ethnographic interview. Orlando, FL: Harcourt Brace Jovanovich College Publishers.

Skinner, E. A. (2010). Project Nueva Generacion and grow your own teachers: Transforming schools and teacher education from the inside out. Teacher Education Quarterly, Summer, 155-167.

Tan, E., and Calabrese Barton, A. (2012). Empowering science and mathematics education in urban schools. Chicago, IL: University of Chicago Press.

Vasquez, O. A., Clark, E. R., and Flores, B. B. (2014). Una pedagogia transmundial/A transworld bedagogy: anchoring theory to the sacred sciences. In Flores, B. B., Vasquez, O. A., Clark, E. R. (Eds.), Generating transworld pedagogy (pp. 17-32). New York, NY: Lexington Books.

Alterstice-Revue Internationale de la Recherche Interculturelle, vol. 6, $n^{\circ} 1$ 
Wassell, B. A., Martin, S. N., and Scantlebury, K. (2013). Using cogenerative dialogues to foster community and support English language learner students' learning. TESOL, 4(4), 759-771.

Zeichner, K. (2010a). Competition, economic rationalization, increased surveillance, and attacks on diversity: Neoliberalism and the transformation of teacher education in the US. Teaching and Teacher Education, 26, 1544-1552.

Zeichner, K. (2010b). Rethinking the connections between campus courses and field experiences in college- and university-based teacher education. Journal of Teacher Education, 61, 89-99. 